\title{
Theoretical analysis and development of a mechanism with punching device for transplanting potted vegetable seedlings
}

\author{
Maile Zhou ${ }^{1,2}$, Yiyin Shan ${ }^{1}$, Xianglei Xue ${ }^{1}$, Daqing Yin ${ }^{1,3 *}$ \\ (1. College of Engineering, Northeast Agricultural University, Harbin 150030, China; \\ 2. School of Agricultural Engineering, Jiangsu University, Zhenjiang, Jiangsu 212013, China; \\ 3. Key Laboratory of Modern Agricultural Equipment Technology in Northern Cold Region, Harbin 150030, China)
}

\begin{abstract}
Several studies have indicated that potted vegetable seedling transplanting technology can greatly improve the ability of vegetable seedlings to resist cold, flood, drought, saline-alkali and pests. The existing transplanting equipment mostly adopts mechanical, electrical and hydraulic integration technologies with a complex structure and a high cost. To address the problems of the complex structure and low efficiency of existing transplanting equipment, a rotary transplanting mechanism for potted vegetable seedlings was developed through configuration analysis and optimization design. Through kinematic analysis of the transplanting mechanism, optimization design software was developed, and the parameters were optimized. A mechanism was developed for picking, transporting, hole punching and transplanting potted vegetable seedlings. The virtual simulation results showed that the maximum error of attitudes of the transplanting arm is less than $1.19^{\circ}$ and that of the hole punching shovel is less than $1.7^{\circ}$. In this study, perforation, seedling harvesting and transplanting experiments were conducted through a bench test. The results showed that the specific trajectory and attitude of the potted vegetable seedlings transplanting mechanism conformed to the requirements of potted vegetable seedling transplantation and the success rate of seedling picking was $92.4 \%$, which verified the correctness and feasibility of the rotary potted vegetable seedling transplanting mechanism.
\end{abstract}

Keywords: planting machinery, transplanting mechanism, potted vegetable seedling, punching device, trajectory and attitude DOI: $10.25165 /$ j.ijabe.20201304.5404

Citation: Zhou M L, Shan Y Y, Xue X L, Yin D Q. Theoretical analysis and development of a mechanism with punching device for transplanting potted vegetable seedlings. Int J Agric \& Biol Eng, 2020; 13(4): 85-92.

\section{Introduction}

The process of potted vegetable seedling transplantation is that vegetable seedlings with nutritional soil are planted into the field or greenhouse by the transplanting arm, which can complete a series of actions, including picking, transporting, hole punching, and planting, which require the special trajectory and attitude ${ }^{[1]}$. In the international market, the majority of potted vegetable transplanting machines are developed with the mechanical, electrical and hydraulic integrated system, completing the actions of picking and feeding seedlings by manual labor or some other arrangement, and then the transplanter completes soil covering and soil compacting, and the working efficiency generally is $30-60$ plants $/ \mathrm{min} /$ row $^{[2-4]}$. Kumar and Raheman ${ }^{[5,6]}$ reported that a fully automatic vegetable transplanter for individual paper pot seedlings was developed, which carried 108 seedlings on two feeding conveyors in an upright orientation, fed them to the conveyors and planted these seedlings in an upright orientation in furrows. The working capacity of this transplanter is approximately $30-40$ plants/min/row. Gutiérrez et

Received date: 2019-09-18 Accepted date: 2020-05-25

Biographies: Maile Zhou, PhD, Lecturer, research interests: design and optimization of agricultural institutions, Email: zhoumaile@126.com; Yiyin Shan, Master candidate, research interests: transplanting equipment, Email: 421247000@qq.com; Xianglei Xue, Master candidate, research interests: transplanting equipment, Email: 1409006771@qq.com.

*Corresponding author: Daqing Yin, PhD, Associate Professor, research interests: transplanting equipment. College of Engineering, Northeast Agricultural University, Harbin 150030, China. Tel: +86-451-55190971, Email: 63900962@qq.com. al. ${ }^{[7]}$ indicated that a transplanting mechanism for strawberry plants was designed, consisting of a cutter, a hook and a clamp to automatically complete operations of cutting the plastic, hide the cut plastic and insert the plant in the ground. The placements of the plants have been reported to be satisfactory in $95 \%$ of the experiments. In the Kubota-type transplanter, a sophisticated mechanism consisting of sliders, cam and links is used to realize the trajectory of seedling-picking and planting, with feeding the vegetable seedlings automatically. The planting rate was found to be 60 plants/min/row. A vertical descending cup-type transplanter of Renaldo Sales and Services Inc. has been studied for vegetable seedlings, which is combined with an injector assembly to punch a planting hole in the plastic mulch. The PVPHR2-type vegetable transplanter has been invented by researchers at Iseki Co. Ltd., which completes the trajectory and attitude required for vegetable seedling transplantation using a dimensional seven-bar linkage mechanism.

Because of its late start, research on potted vegetable seedling transplanting mechanisms in China has a long way to go compared with that in developed countries, such as Europe and the United States. A kinematic model of the seedling transplanting machine with the deformed elliptical geared seven-bar linkage mechanism was established, and optimization software was developed to obtain a group of optimized parameters for a seedling transplanting mechanism ${ }^{[8,9]}$. A single row automatic transplanting device and a tray-seedling sorting transplanter was developed ${ }^{[10,11]}$. A vegetable plug seedling pick-up mechanism involving a planetary gear train with ellipse gears and an incomplete non-circular gear was designed by $\mathrm{Yu}$ et al. ${ }^{[12,13]}$. Wang et al. ${ }^{[14,15]}$ designed an 
automatic potted vegetable seeding transplanter for dry land. Ye et al. ${ }^{[16,17]}$ and $\mathrm{Yu}$ et al. ${ }^{[18]}$ completed the parameter optimization of a pick-up mechanism according to the particular trajectory and attitude required by the potted vegetable seedling transplanting mechanism. Zhou et al. ${ }^{[19,20]}$ reported a rice potted seedling transplanting mechanism with planetary Bezier gears that was designed using a fitted Bezier curve as a non-circular gear pitch cure; thus, a physical prototype was assembled, and the seedling pick-up experiment was conducted. Wang et al. ${ }^{[21]}$ developed a crank-rocker type seedling clamping mechanism according to corresponding requirements, which was driven by an adjustable-speed motor and a crank. The rocker clamper designed as a reciprocating swing cloud completes transplanting actions, such as picking-up and planting seedlings in cooperation with an ejection mechanism. Cui et al. ${ }^{[22]}$ designed a geared five-bar linkage seedling pick-up device, and its ideal trajectory was obtained through the simulation and optimization of structural parameters. Liu et al. ${ }^{[23]}$ designed a planetary five-bar planting mechanism for zero-speed transplanting on mulch film. The vegetable seedling picking up bench was designed to verify the validity and feasibility of the geared five-bar linkage seedling pick-up device.

Manual transplanting on a large commercial scale is labor-intensive, expensive, and often does not result in uniform distribution of plants compared with a mechanical transplanter ${ }^{[24]}$. A well-performing seedling transplanter has not been applied widely, primarily because of problems with higher levels of site preparation, flexible standard trays, cost, and operating results ${ }^{[25]}$. To overcome these factors, a fully automatic transplanter will be improved to plant various vegetable seedlings. One key point in the development of an improved vegetable seedling transplanting mechanism is to continue strengthening the cooperation of horticulturists and agricultural engineers.

To adapt to the national condition and market of China, the objective of this work was to design a fully automatic rotary potted vegetable seedling transplanting mechanism with a punching device based on configuration analysis and optimal design, which operates only one mechanism to complete the actions of picking, transporting, punching the hole and planting. In addition, a performance experiment was conducted to verify the validity and feasibility of each approach.

\section{Working principle}

\subsection{Transmission scheme and working principle}

The designed hole punching and transplanting mechanism are based on a non-circular gear transmission combined with a four-bar mechanism as the core components of the potted vegetable seedling transplanter. The complicated trajectory and attitude of the three actions, picking, transporting and planting, were performed by the non-circular variable speed planetary gear train, which actuates the four-bar mechanism to complete the complicated trajectory and attitude for punching the hole.

As shown in Figure 1, sun gear (7) was installed on the framework, and the intermediate gear $(5,8)$ and planetary gear $(3$, 10) vertically hinged on planetary framework 6 . The sun gear (7) and planetary gear $(3,10)$ meshed with intermediate gear $(5,8)$. The transplanting arm $(1,9)$ is fixed on planetary gear $(3,10)$, and the punching shovel $(4,12)$ was connected to the transplanting arm $(1,9)$ via a hinge joint. One end of connecting rod $(2,11)$ was hinged with planetary framework 6 , and the other was connected with punching shovel $(4,12)$. When the transplanting machine is working, the planetary framework rotates clockwise, and the "olecranon-type" relative movement trajectory is formed by the cusp point of the transplanting arm through the meshing of the sun gear, intermediate gear and planetary gear. In addition, by the variable-speed transmission of the four-bar mechanism connected to the punching shovel, the cusp point of the shovel forms a relative movement trajectory in the shape of a "boots".

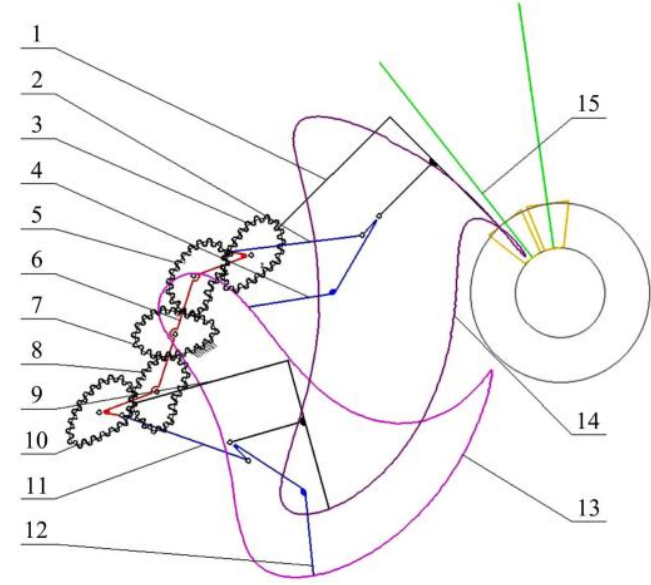

$\begin{array}{llll}\text { 1. Transplanting arm I } & \text { 2. Connecting rod I } & 3 \text {. Planetary gear I } & \text { 4. Punching }\end{array}$ shovel I 5. Intermediate gear I 6. Planetary framework 7. Sun gear 8. Intermediate gear II 9. Transplanting arm II 10. Planetary gear II 11. Connecting rod II 12. Punching shovel II 13. The boots-type punching trajectory 14. The "olecranon-type" transplanting trajectory 15. Potted vegetable seedlings

Figure 1 Transmission scheme of the potted seedling transplanting mechanism

The mechanical functions of an innovative transplanting arm are to perform the actions of seedling-picking and pushing of the seedlings. The transplanting arms are the components in direct contact with the seedlings in the mechanism. The transplanting arm consists of a fork, a seedling-pushing rod, a cam, a compression spring, and a frame, as shown in Figure $2 \mathrm{a}$. In a work cycle of seedling picking, fork (2) is pushed by the lift section of cam (9) oscillating anticlockwise relative to transplanting arm (1), the other end of the fork (2) compresses the seedling-pushing spring (8) via spring seat (3), and then the seedling-pushing rod (4) fixed on spring seat (3) moved to the left The seedling-picking device (5), fixed with the right end of the seedling-pushing rod (4), moves to left along with the seedling-pushing rod (4); thus, the seedling-picking clamp (6) closes and then picks up the vegetable seedlings. While the transplanting mechanism performs the action of seedling discharging, the fork (2) motions to the return stroke of cam (9) and triggered by compression spring (8), which oscillates clockwise relative to the transplanting arm (1). Therefore, the seedling-pushing rod (4) motions to the right through spring seat (3). Under the motion of the seedling-picking device (5), the seedling-picking clamp (6) opens to release the seedlings. Figure $2 \mathrm{~b}$ shows the working condition of the transplanting arm for seedling picking, seedling pushing and the initial state. In the initial position, the opening of the seedling-picking clamp is $d_{1}$ less than the surface width of the substrate, and the clamp ready to penetrate into the root mass within the growing tray cell for seedling extraction. After picking up the seedlings, the seedling-picking clamp opening distance is $d_{2}$, and then the transplanting arm transfers the seedlings to the planting position. After completing seedling pushing, the seedling-picking clamp opening distance is $d_{3}$. Additionally, the seedlings would be 
discharged and set into the hole punched by the shovel.
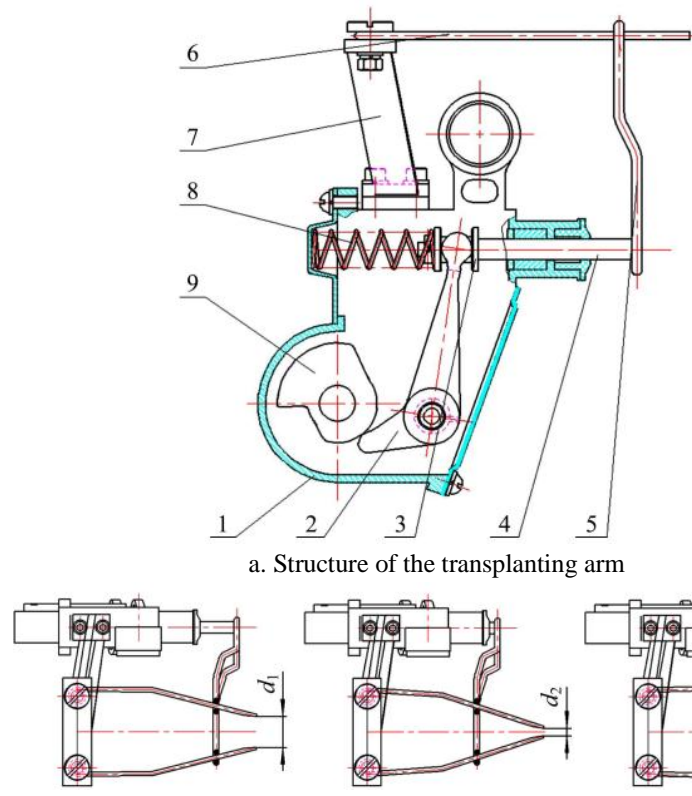

b. State diagram

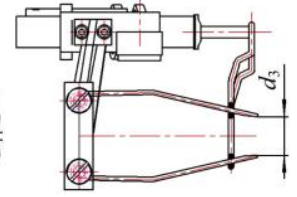

1.Transplanting arm 2. Fork 3. Spring seat 4. Seedling-pushing rod 5. Seedling-picking device 6. Seedling-picking clamp 7. Holder 8. Seedling-pushing spring 9. Cam

Figure 2 Structure of the transplanting arm and the working states

\subsection{Description of operating period and trajectory analysis}

The potted vegetable seedling transplanting mechanism is assembled with two transplanting arms (the phase angle is $180^{\circ}$ ), which completes two transplanting processes in a work cycle. The upper transplanting arm is an example to explain the operating period. Firstly, in the initial position, the angular displacement of the planetary frame is $126.5^{\circ}$. When the planetary frame rotates clockwise by $55^{\circ}$ from its initial position, the seedling-picking clamp penetrates into the growing tray for seeding extraction. When the planetary frame turns $58^{\circ}$ from its initial position, the seedling-picking clamp begins to close for clamping the seedling stem. When the planetary frame has rotated $91^{\circ}$, the seedling-picking clamp is completely closed to finish the action of clamping seedlings. Then, the planetary frame rotates clockwise $111^{\circ}$, and the seedling-picking clamp extracts vegetable seedlings from the growing tray. Furthermore, the rotation angle of the planetary angle is $200^{\circ}$, and the punching shovel moves to the ground and operates to punch the hole. When the rotation angle of the planetary frame relative to the initial position is $243^{\circ}$, the seedling-pushing rod starts working while the seedling-picking clamp opening in preparation for discharging the seedlings. Then, the planetary frame rotates $248^{\circ}$, the seedling-picking clamp completely opens and the seedling-pushing rod moves forward to push the soil blocks of vegetable seedlings into the hole to complete the seedling transplanting action. Finally, while the relative angle of the planetary frame is $279^{\circ}$, and the punching shovel exits from the soil to complete the action of punching the hole. Therefore, the planetary frame rotates to the initial position, indicating that an operating period has been completed.

The trajectory of the transplanting arm and the punching shovel are shown in Figure 3. Figure 3a indicates the relative motion trajectory, and the absolute motion trajectory is shown in Figure $3 b$. The process of seedling picking is shown in section $\mathrm{AB}$, and the cusp point of the transplanting arm penetrates the growing tray for seedling extraction. The action of transporting is operating in the $\mathrm{BC}$ section, and the seedling is transported from the pick-up position to the planting point by the transplanting arm, which rotates a certain angle that is substantially the same as the dip angle of the seedling box. In the CA section, the transplanting arm completes the seedling-pushing process and prepares for the next transplanting action.

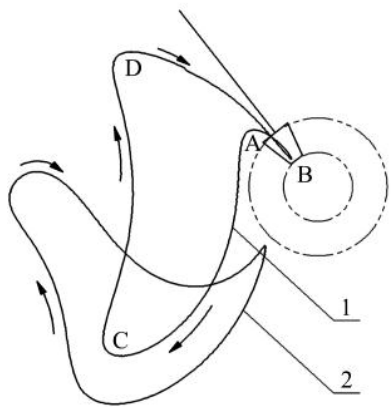

a. Relative motion trajectory

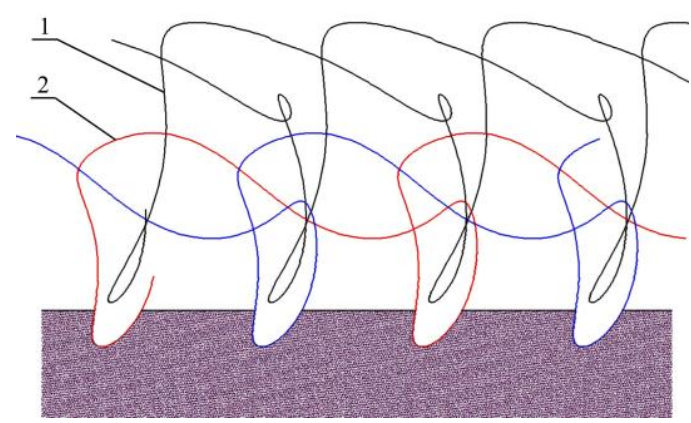

b. Absolute motion trajectory

1. Trajectory of the transplanting arm $\quad 2$. Trajectory of the shovel

Figure 3 Trajectory of the relative motion and the absolute motion

\subsection{Kinematics analysis}

With the rotary center of the sun gear as the origin for the coordinates, the kinematic analysis model of the potted vegetable seedling transplanting mechanism was established. While analyzing the four-bar mechanism that is used to punch the hole, the relative coordinate system $x^{\prime} O_{3} y^{\prime}$ moving with the transplanting arms was established based on the rotary center of the planetary gear as the origin point, as shown in Figure 4. Thus, kinematic analysis of the transplanting arm and punching shovel was performed by analyzing the upper transplanting arm and upper four-bar mechanism, which is rotated $180^{\circ}$ with the planetary framework to a position of the under transplanting arm and the under the four-bar mechanism, respectively. Assuming the angular displacement of the planetary frame is $\varphi_{H}(i)$.

Upper-intermediate gear rotates clockwise relative to planetary frame:

$$
\varphi_{2 H}(i)=\sum_{j=0}^{i-1} \frac{r_{1}(j)}{r_{2}(j)} \cdot\left|\left[\varphi_{1 H}(j+1)-\varphi_{1 H}(j)\right]\right|
$$

Due to the corner $\alpha_{0}$ of the frame, the rotation angle of the upper planetary gear relative to the frame is $\varphi_{30}$ :

$$
\varphi_{30}=\varphi_{i_{0}}
$$

$\varphi_{i 0}$ satisfying $\left|\varphi_{2 H}\left(i_{0}\right)-\alpha_{0}\right|<\varepsilon_{2}$.

Upper planetary gear rotates counterclockwise relative to the planetary frame:

$$
\varphi_{3 H}(i)=\sum_{j=0}^{i-1} \frac{o_{1} o_{2}-r_{2}(j+\pi)}{r_{2}(j+\pi)} \cdot\left[\varphi_{2 H}(j+1)-\varphi_{2 H}(j)\right]
$$

Absolute angular displacement of the upper intermediate gear:

$$
\varphi_{2}(i)=\varphi_{H}(i)-\varphi_{2 H}(i)
$$

Absolute angular displacement of the upper planetary gear: 
$\varphi_{3}(i)=\varphi_{H}(i)+\varphi_{3 H}(i)+\alpha_{0}+\varphi_{30}$

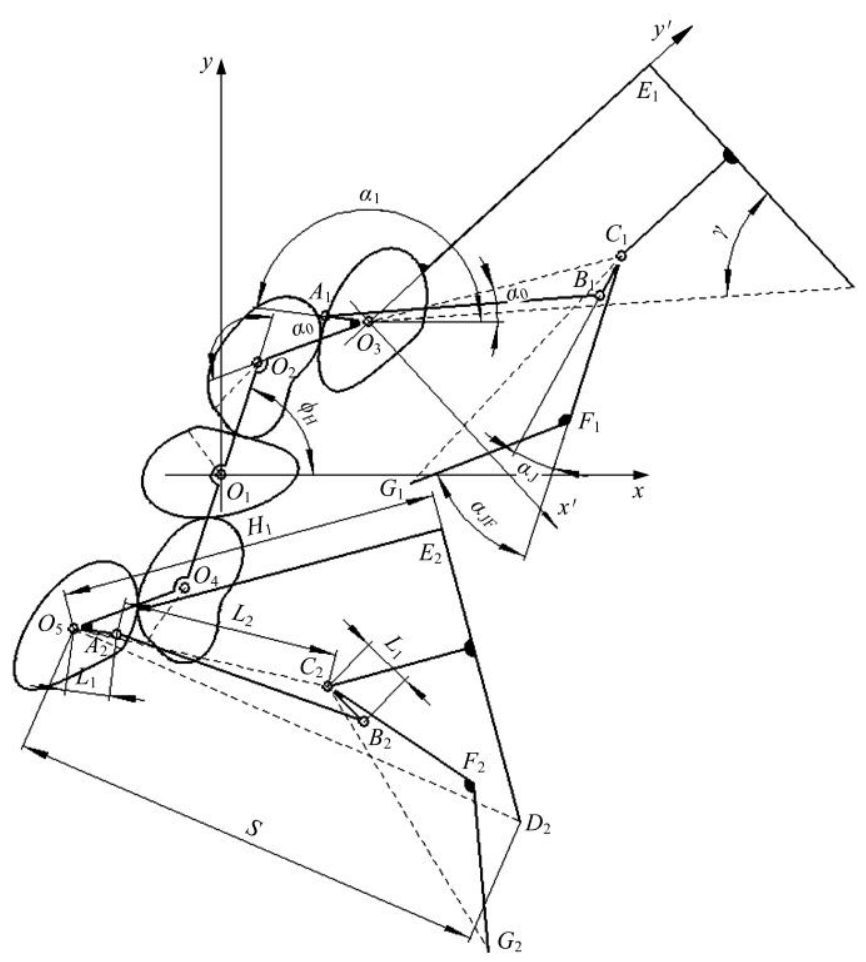

Figure 4 Schematic diagram of the potted vegetable seedling transplanting mechanism

Coordinate of the cusp point $D_{1}$ of the upper transplanting arm:

$$
\left\{\begin{array}{l}
x_{D 1}(i)=x_{o 3}(i)+S \cdot \cos \left[\varphi_{H}(i)+\alpha_{0}+\varphi_{3 H}(i)+\delta_{0}\right]+i \cdot H / \pi \\
y_{D 1}(i)=y_{o 3}(i)+S \cdot \sin \left[\varphi_{H}(i)+\alpha_{0}+\varphi_{3 H}(i)+\delta_{0}\right]
\end{array}\right.
$$

where, $H$ is the planting spacing.

The absolute motion coordinate of the cusp point $G_{1}$ of the upper punching shovel can be obtained as:

$$
\left\{\begin{array}{l}
x_{G 1}(i)=x_{C 1}(i)+L_{C G} \cdot \cos \left[\theta_{2}(i)+\pi+\alpha_{J}\right]+i \cdot H / \pi \\
y_{G 1}(i)=y_{C 1}(i)+L_{C G} \cdot \sin \left[\theta_{2}(i)+\pi+\alpha_{J}\right]
\end{array}\right.
$$

where, $\alpha_{J}$ is the corner of the punching shovel.

\section{Establishment of the objectives and optimization parameters}

In terms of the optimized design for the specific trajectory and attitude, the computation is large, and the accurate calculation is required. Combined with the characteristics of potted vegetable seedling transplanting, the transplanting process has been divided into picking, transporting, pushing the hole and planting. The movement requirements of each stage have been analyzed. The characteristic information of the trajectory and attitude of each stage has been extracted, such as the attitude of transplanting arm during picking and planting, the height of the trajectory and the angle of the punching shovel during entering the soil, etc. Based on the kinematic model of the transplanting mechanism and the agronomic requirements of potted vegetable seedling transplanting, the parameters of transplanting mechanism have been taken as independent variables, and the trajectory and attitude required by transplanting agronomic requirements have been transformed into optimization objectives. The function relationship between mechanism parameters and optimization objectives had been established to converted the agricultural requirements of potted vegetable seedlings into numerical optimization objectives, the following objective requirements were considered: 1) The distance between the two transplanting arms in the nearest position is $S_{1}$ >
$5 \mathrm{~mm}$; 2) The picking-seedling angle $\lambda_{1}$ is approximately $310^{\circ}-320^{\circ}$; $3)$ the pushing-seedling angle $\lambda_{2}$ is approximately $260^{\circ}-280^{\circ}$; 4) the angle difference $\lambda_{3}$ is approximately $40^{\circ}-60^{\circ}$; 5) the nearest distance between the potted seedling and the tray in the transporting process is $S_{2}>5 \mathrm{~mm} ; 6$ ) the seedling-pushing altitude of transplanting arm is $S_{3}>75 \mathrm{~mm}$; 7) the distance between the gearbox and the ground is $S_{4}>25 \mathrm{~mm} ; 8$ ) the height difference of the trajectory is $S_{5}>260 \mathrm{~mm}$; 9) When extracting the seedling from the growing tray, the distance between the bottom of the tray cell and the root soil of the seedling is $S_{6}>45 \mathrm{~mm} ; 10$ ) the gear modulus is $m>2.5 \mathrm{~mm}$; 11) the nearest distance between the punching shovel and the growing tray is $S_{7}>5 \mathrm{~mm}$; 12) the nearest distance between the upper (under) punching shovel and under (upper) transplanting arm is $S_{8}>5 \mathrm{~mm} ; 13$ ) the width of hole $\mathrm{S} 9$ is approximately 50 $80 \mathrm{~mm} ; 14$ ) the depth of hole $S_{10}$ is approximately $47-60 \mathrm{~m} ; 15$ ) the seedling-pushing altitude of the punching shovel is $S_{11}>45 \mathrm{~mm} ; 16$ ) the offset between the hole and the seedlings is $S_{12}<10 \mathrm{~mm}$; 17) the traverse offset of the middle and the lowest position in the hole is $\left.S_{13}<10 \mathrm{~mm} ; 18\right)$ the penetration angle $\lambda_{4}$ of the punching shovel is approximately $260^{\circ}-280^{\circ}$; 19) the angular deviation of the punching shovel and the seedling pushing $\left.\lambda_{5}>5^{\circ} ; 20\right)$ the swinging angle of the transplanting arm during the picking seedling procedure is $\left.\lambda_{6}<10^{\circ} ; 21\right)$ the nearest distance between the hinge point and the ground is $S_{14}>25 \mathrm{~mm}$.

An analysis and optimization software was programmed for the potted vegetable seedling transplanting mechanism based on the kinematic model and the optimized objectives, as shown in Figures 5 and 6 . The visual interface of the analysis and optimization software includes a graphic display area, parameter area, optimization target area, step adjustment area, etc. The graphic display area can be switched in the initial position module, relative motion module, absolute motion module and speed analysis module of the transplanting mechanism. The "parametric guidance" heuristic optimization algorithm was embedded in the software, which solved a complex optimization problem of the special trajectory and attitude of potted vegetable seedling transplantation. Therefore, a set of optimized parameters satisfying the operational planting requirements was obtained that can be listed as follows: $r_{1}=27.5 \mathrm{~mm} ; \theta_{1}=18.7^{\circ} ; r_{2}=46.4 \mathrm{~mm}$; $\theta_{2}=32^{\circ} ; r_{3}=68 \mathrm{~mm} ; \theta_{3}=77.5^{\circ} ; r_{4}=45.3 \mathrm{~mm} ; \theta_{4}=106.5^{\circ} ; r_{5}=17.3 \mathrm{~mm}$; $\theta_{5}=136^{\circ} ; r_{6}=30 \mathrm{~mm} ; \theta_{6}=166.5^{\circ} ; r_{7}=47.1 \mathrm{~mm} ; \theta_{7}=213^{\circ} ; r_{8}=40.3 \mathrm{~mm}$ $\theta_{8}=245^{\circ} ; r_{9}=70.6 \mathrm{~mm} ; \theta_{9}=244.5^{\circ} ; r_{10}=27.9 \mathrm{~mm} ; \theta_{10}=257^{\circ} ; r_{11}=$ $15.8 \mathrm{~mm} ; \theta_{11}=311.5^{\circ} ; r_{12}=26.3 \mathrm{~mm} ; \theta_{12}=336^{\circ} ;$ fai $_{0}=126.5^{\circ} ;$ det $_{0}=$ $-55^{\circ} ; S=222 \mathrm{~mm} ; H_{1}=174 \mathrm{~mm} ;$ afai $_{0}=-51.6^{\circ} ; H=203 \mathrm{~mm}$.

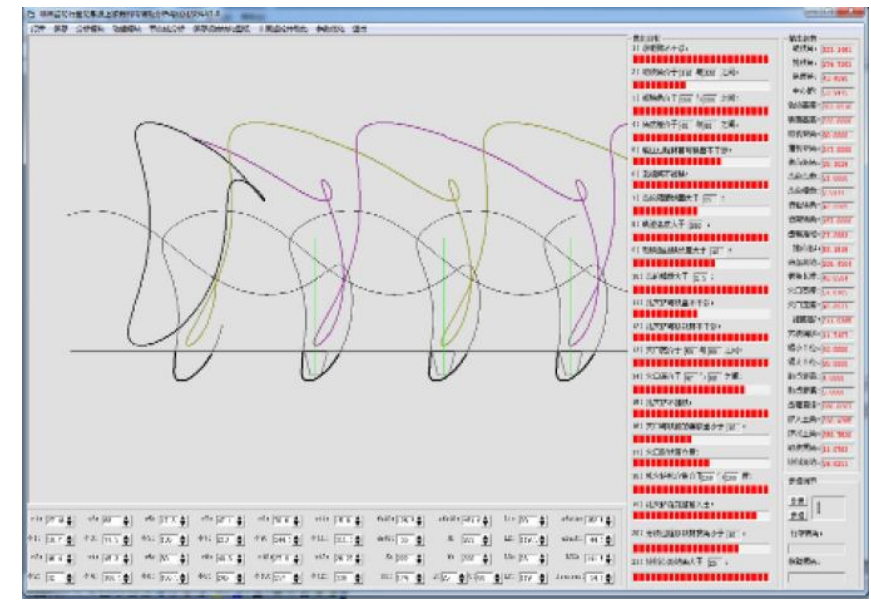

Figure 5 Analysis and optimization software for the transplanting mechanism 


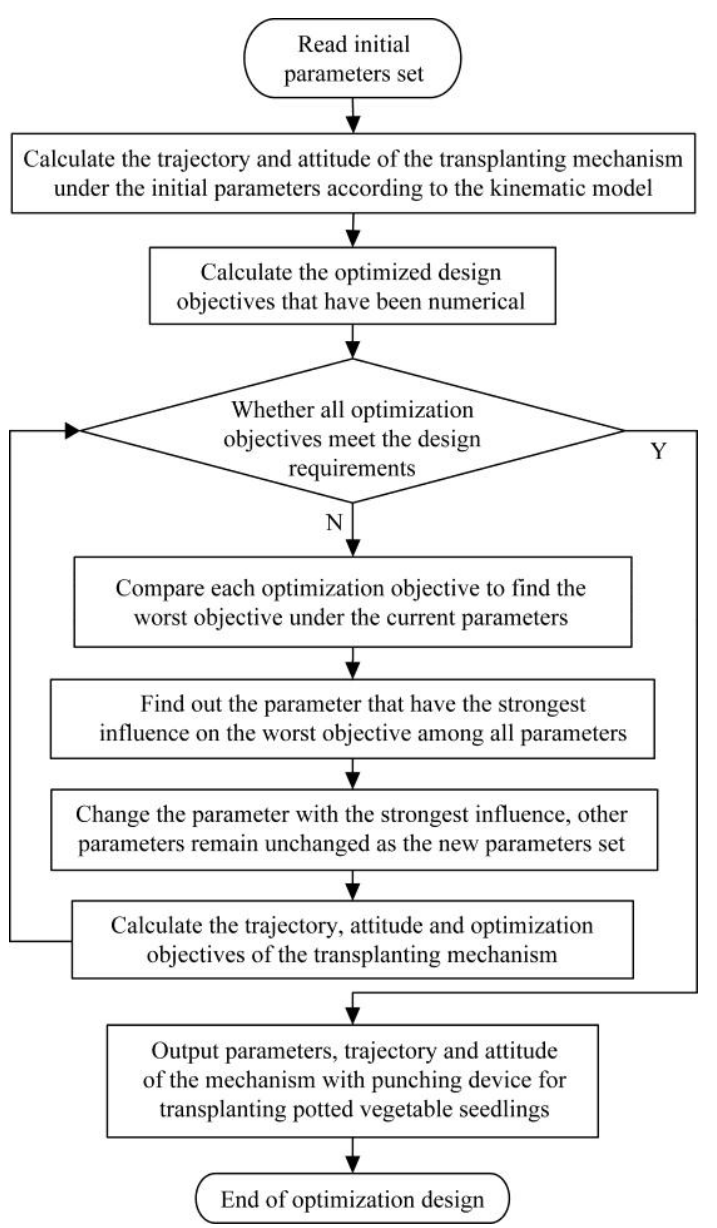

Figure 6 Flow chart of the optimization software

The output parameters of the optimized objectives met the requirements of potted seedling transplantation, and the numerical objectives as shown in Table 1.

Table 1 Numerical objectives

\begin{tabular}{ccccccc}
\hline Symbol & $S_{1} / \mathrm{mm}$ & $\lambda_{1} /\left(^{\circ}\right)$ & $\lambda_{2} /\left(^{\circ}\right)$ & $\lambda_{3} /\left(^{\circ}\right)$ & $S_{2} / \mathrm{mm}$ & $S_{3} / \mathrm{mm}$ \\
\hline Target values & 11.56 & 323.24 & 279.75 & 43.48 & 92.68 & 53.16 \\
\hline \hline Symbol & $S_{4} / \mathrm{mm}$ & $S_{5} / \mathrm{mm}$ & $S_{6} / \mathrm{mm}$ & $m / \mathrm{mm}$ & $S_{7} / \mathrm{mm}$ & $S_{8} / \mathrm{mm}$ \\
\hline Target values & 27.23 & 353.02 & 40.62 & 2.7 & 91.98 & 130.68 \\
\hline Symbol & $S_{9} / \mathrm{mm}$ & $S_{10} / \mathrm{mm}$ & $S_{11} / \mathrm{mm}$ & $S_{12} / \mathrm{mm}$ & $S_{13} / \mathrm{mm}$ & $\lambda_{4} /\left(^{\circ}\right)$ \\
\hline Target values & 57.95 & 45.89 & 211.93 & 7.86 & 19.54 & 275.11 \\
\hline
\end{tabular}

\section{Experiment}

\subsection{Manufacture and simulation for the virtual prototype}

According to the software-optimized parameters, the structure design of the potted vegetable seedling transplanting mechanism had been completed, and the virtual prototype was established, which was imported into ADAMS to perform the virtual prototype experiment, as shown in Figure 7. The trajectory of the transplanting mechanism and the velocity curve were obtained to verify the correctness of establishing the virtual prototype.

\subsection{Manufacture of the experiment bench system and physical prototype}

A transplanting test bench system was independently developed by our research group, and we manufactured the physical prototype of the transplanting mechanism based on 3D printing technology, which includes the Cubepro 3D printer, PLA materials and printing layer accuracy of 70 microns, as shown in Figure 8 . The experiment system was driven by a motor, and a series of experiments, such as trajectory verification, seedling picking and transplanting, were completed.

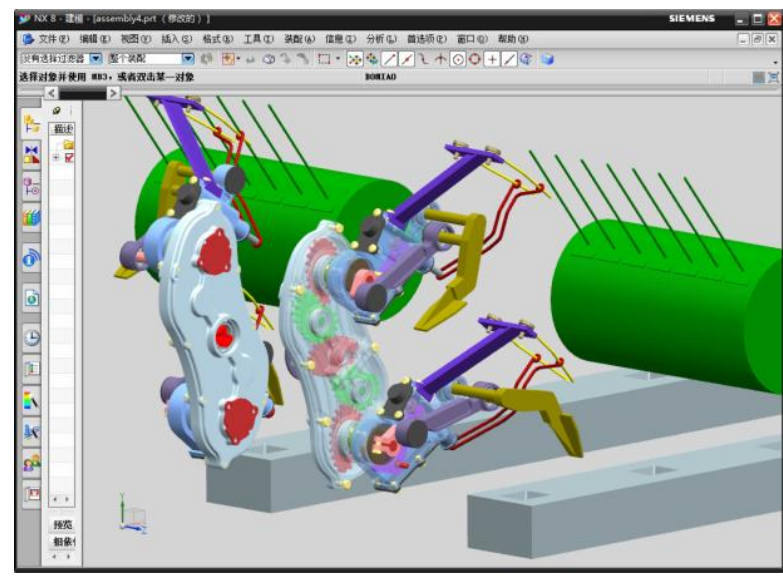

a. Virtual prototype

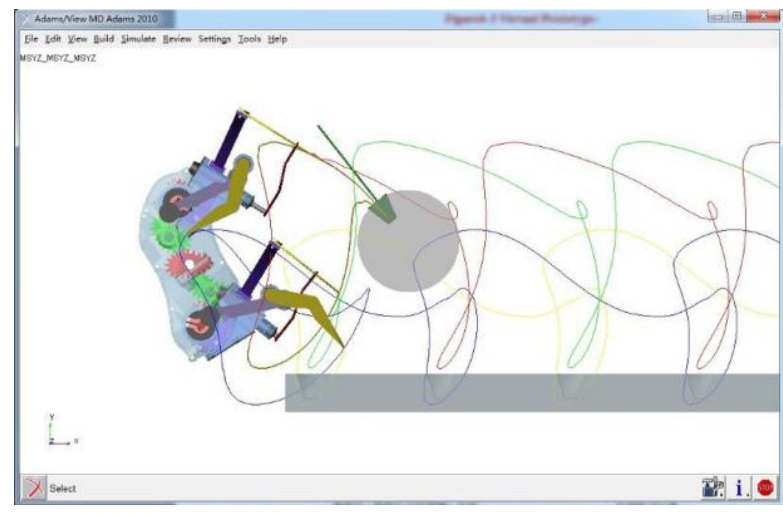

b. Virtual prototype experiment

Figure 7 Virtual prototype experiment for the potted vegetable seedling transplanting mechanism

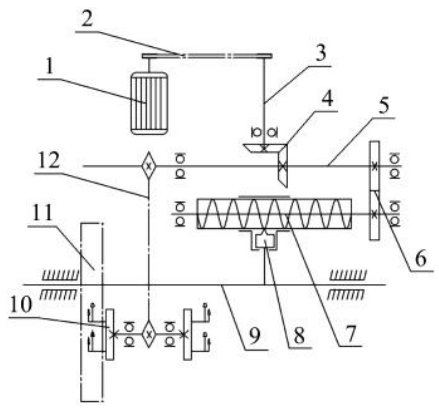

a. Diagram of the transmission system for the test bench

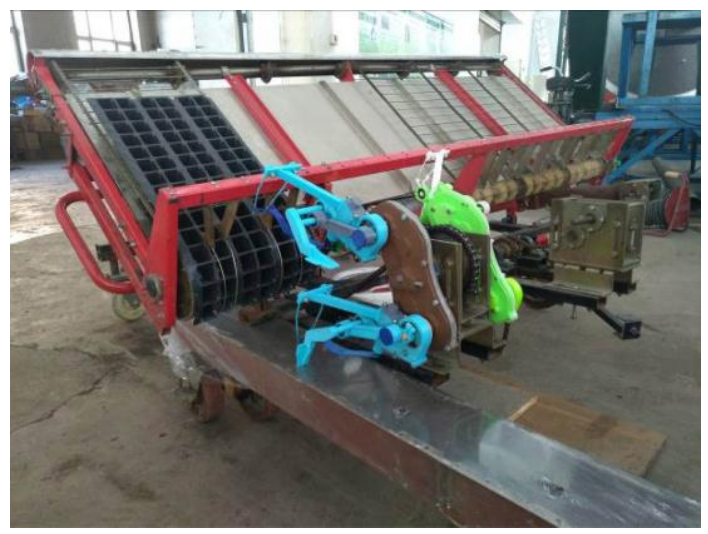

b. Test bench

1. Motor 2. Transmission belt 3. Driving shaft 4. Bevel gear pair 5. Driven shaft 6. Circular gear pair 7. Screw shaft 8 . Sliding block 9. Seedling box 10. Transplanting mechanism 11. Soil bin 12. Chain transmission

Figure 8 Test bench for the potted vegetable seedling transplanting mechanism 


\subsection{Verification of the trajectory and attitude}

The verification experiment of the "olecranon-type" relative motion trajectory of the transplanting arm cusp point and the "boots-type" relative motion trajectory formed by the punchinghole shovel cusp point were completed. The rotation speed of the planetary frame was set to $100 \mathrm{r} / \mathrm{min}$ (200 plants/min/row), and high-speed photographic equipment was used to photograph the operation of the potted vegetable seedling transplanting mechanism, as shown in Figure 9. Then, the relative motion trajectory of the physical prototype was obtained, which was consistent with the trajectory of the optimization software (Figure 9a) and the virtual prototype simulation (Figure 9b), respectively.

The attitude of the key positions, including the clamp entering growing tray, picking-seedling, planting and hole punching, was a pivotal issue in the design of the transplanting mechanism.

As shown in Figure 10, the images of various key positions, such as the clamp starting to penetrate into the tray, the beginning of seedling clamping, the end of seedling clamping, the clamp lifting the seedling out the tray cell, the starting of punching the hole, the beginning of planting, the end of planting and the end of punching, were obtained by analyzing the high-speed photography experiment. The cusp trajectory of the transplanting arm (Table 2) and the attitude of the punching shovel (Table 3) were compared with the conclusions of optimization software. The results were found to be basically consistent, so the correctness of the theoretical analysis, optimization software, virtual prototype simulation and physical prototype were verified by the consistency of the special trajectory and attitude.

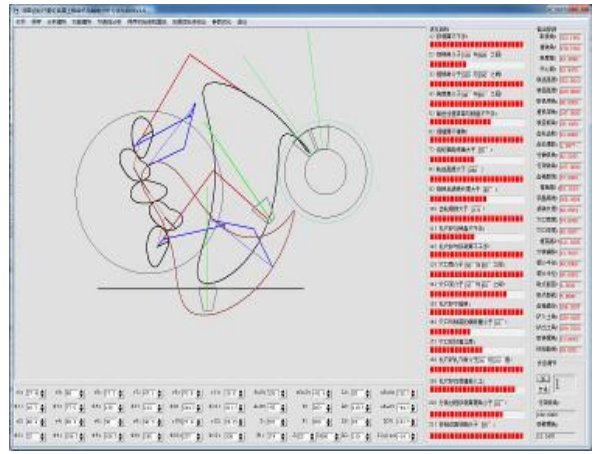

a. Optimization software

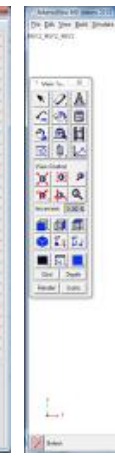

b. Virtual prototype simulatio

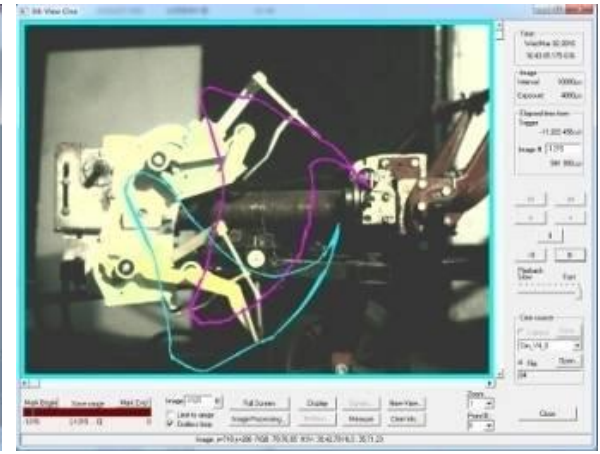

c. High-speed photography experiment

Figure 9 Comparison of the relative motion trajectory

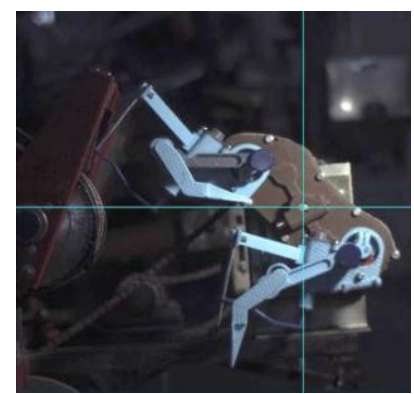

Clamp starting to penetrate into the tray

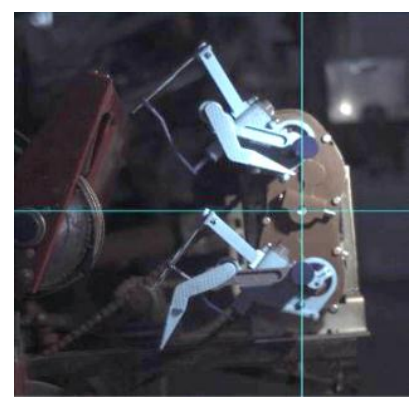

Starting of hole punching

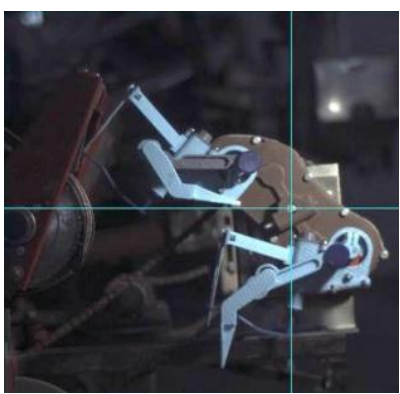

Beginning of seedling clamping

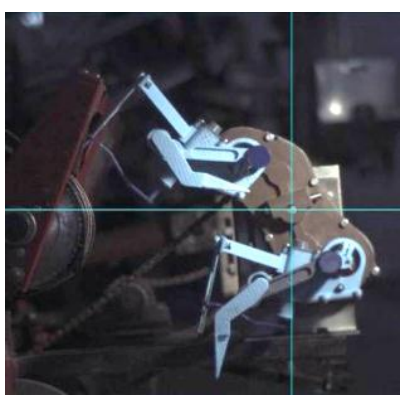

Beginning of planting

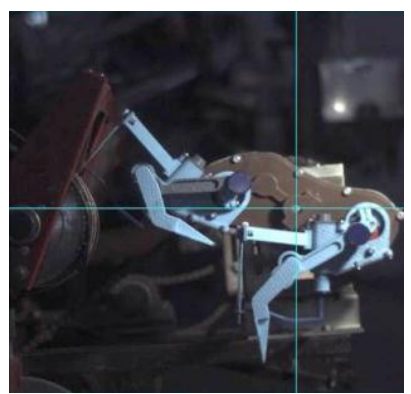

End of seedling clamping

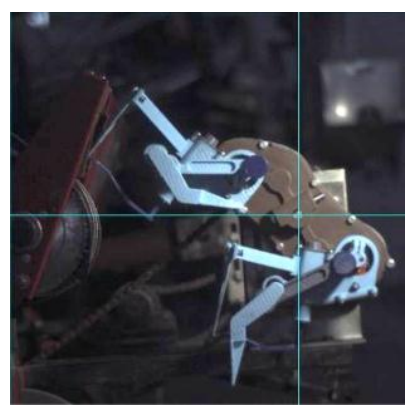

End of planting

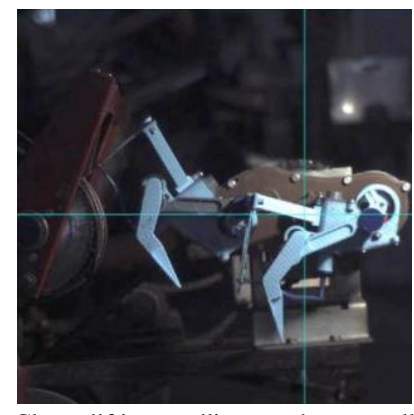

Clamp lifting seedling out the tray cell

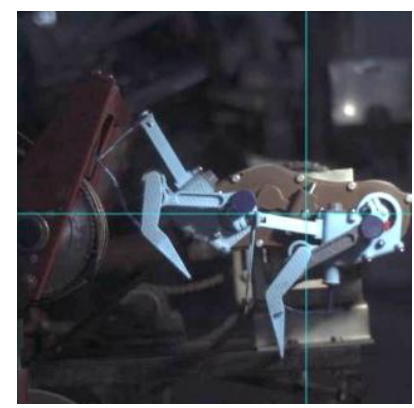

End of hole punching

Figure 10 Attitudes of the key positions

Table 2 Attitudes of the transplanting arm $\left(^{\circ}\right)$

\begin{tabular}{|c|c|c|c|c|c|c|c|c|}
\hline Data source & $\begin{array}{l}\text { Clamp penetrating } \\
\text { into the tray }\end{array}$ & $\begin{array}{c}\text { Beginning of } \\
\text { seedling clamping }\end{array}$ & $\begin{array}{l}\text { End of seedling } \\
\text { clamping }\end{array}$ & $\begin{array}{l}\text { Clamp lifting the } \\
\text { seedling out of the tray }\end{array}$ & $\begin{array}{l}\text { Start of hole } \\
\text { punching }\end{array}$ & $\begin{array}{l}\text { Beginning of } \\
\text { planting }\end{array}$ & $\begin{array}{l}\text { End of } \\
\text { planting }\end{array}$ & $\begin{array}{l}\text { End of hole } \\
\text { punching }\end{array}$ \\
\hline Software & 6.41 & 6.26 & 14.15 & 30.46 & 359.72 & 333.11 & 330.94 & 333.77 \\
\hline
\end{tabular}

Table 3 Attitudes of the hole punching shovel $\left({ }^{\circ}\right)$

\begin{tabular}{|c|c|c|c|c|c|c|c|c|}
\hline Data source & $\begin{array}{l}\text { Clamp penetrating } \\
\text { into the tray }\end{array}$ & $\begin{array}{c}\text { Beginning of } \\
\text { seedling clamping }\end{array}$ & $\begin{array}{l}\text { End of seedling } \\
\text { clamping }\end{array}$ & $\begin{array}{l}\text { Clamp lifting the } \\
\text { seedling out of the tray }\end{array}$ & $\begin{array}{l}\text { Start of hole } \\
\text { punching }\end{array}$ & $\begin{array}{l}\text { Beginning of } \\
\text { planting }\end{array}$ & $\begin{array}{l}\text { End of } \\
\text { planting }\end{array}$ & $\begin{array}{c}\text { End of hole } \\
\text { punching }\end{array}$ \\
\hline Software & 188.77 & 189.61 & 220.06 & 255.25 & 290.88 & 273.31 & 271.63 & 260.26 \\
\hline Test & 188.13 & 189.21 & 221.68 & 254.14 & 289.18 & 272.74 & 270.86 & 259.67 \\
\hline
\end{tabular}




\subsection{Experiment for hole punching}

In the transplanting process, the action of hole punching plays a key role that affects a number of important criteria, for example, the depth of planting and the upright degree. To verify the effect of the punching device, an experiment with hole punching was conducted on the test bench. Since the action of hole punching was irrelevant to the three actions of picking, transporting and planting, to observe conveniently, the seedling box was dismantled while the transplanting mechanism was operating, the transplanting mechanism was rotated relative to the framework, and the soil bin was moved rearward at a constant speed (the transplanting mechanism moved forward relative to the soil bin).

In consideration of the agricultural requirements of the vegetable seedling transplanting and the phenomenon of soil backflows occurring in the process of punching the hole, the three-factor and three-level orthogonal experiments were performed based on the efficiency of transplanting, planting spacing and the penetration depth of the punching shovel as the experimental factors. According to the size of the growing tray and the agriculture, requirements to select the experimental factors shown in Table 4. The size of the hole perpendicular to the working direction of the transplanter was determined by the structure of the punching shovel and the size along the working direction as a key factor to maintain the seedlings in an upright position after transplantation. The condition of the soil moisture content was $7.9 \%-25.7 \%$, the size of the hole along the working direction was used as an objective function to complete the hole punching experiment, and the experimental plan and results are shown in Table 5.

Table 4 Experimental factors and encoding

\begin{tabular}{cccc}
\hline & \multicolumn{3}{c}{ Factors } \\
\cline { 2 - 4 } Levels & $\begin{array}{c}\text { Transplanting efficiency N } \\
\text { /plants } \text { min }^{-1} \cdot \text { row }^{-1}\end{array}$ & $\begin{array}{c}\text { Planting spacing } \\
\mathrm{H} / \mathrm{mm}\end{array}$ & $\begin{array}{c}\text { Penetration depth } \\
\mathrm{L} / \mathrm{mm}\end{array}$ \\
\hline 1 & 100 & 180 & 40 \\
2 & 150 & 200 & 50 \\
3 & 200 & 220 & 60 \\
\hline
\end{tabular}

Table 5 Experimental plan and results

\begin{tabular}{|c|c|c|c|c|}
\hline \multirow{2}{*}{ No } & \multicolumn{3}{|c|}{ Experiment factors } & \multirow{2}{*}{$\begin{array}{l}\text { Response value } \\
\text { Size of the hole }\end{array}$} \\
\hline & A & B & $\mathrm{C}$ & \\
\hline 1 & 1 & 2 & 1 & 51.5 \\
\hline 2 & 3 & 2 & 2 & 60 \\
\hline 3 & 2 & 1 & 2 & 75 \\
\hline 4 & 3 & 1 & 1 & 60 \\
\hline 5 & 1 & 1 & 3 & 81.6 \\
\hline 6 & 2 & 3 & 1 & 40.5 \\
\hline 7 & 3 & 3 & 3 & 59.3 \\
\hline 8 & 2 & 2 & 3 & 65 \\
\hline 9 & 1 & 3 & 2 & 50 \\
\hline$K_{1}$ & 61.03 & 72.2 & 50.67 & \\
\hline$K_{2}$ & 60.17 & 58.83 & 61.67 & \\
\hline$K_{3}$ & 59.77 & 49.93 & 68.63 & \\
\hline Range $R$ & 1.26 & 22.27 & 17.96 & \\
\hline $\begin{array}{l}\text { Primary and secondary } \\
\text { sequence }\end{array}$ & & & $\mathrm{C}>\mathrm{A}$ & \\
\hline Optimal level & $\mathrm{A}_{1}$ & $\mathrm{~B}_{1}$ & $\mathrm{C}_{3}$ & \\
\hline Optimal combination & & & $\mathrm{B}_{1} \mathrm{C}_{3}$ & \\
\hline
\end{tabular}

Tables 4 and 5 show that the biggest effect of the hole is on planting spacing, followed by the penetration depth of the punching shovel, and the impact of the planting efficiency is minimal.
These effects are because the punching shovel has a backward horizontal velocity relative to the mechanism frame when punching the hole, and the transplanting mechanism moves forward, similar to other influencing factors, with the increase in the planting spacing and the transplanter advance speed, the length of the hole and the contact area between the puncture shovel and the ground decreases. When the transplanting efficiency and the planting spacing are constant, the deeper the shovel penetrates into the soil, the longer it would act on the soil and lead to a lengthening hole. A group of the best combination data (A1B1C3) was obtained through the three-factor three-level experiment. However, due to the different agronomic characteristics of different crops, even if the same crop has different agronomic characteristics in different regions, the hole punching experiment can provide a reference for plant spacing and planting depth adjustment.

\subsection{Potted seedling picking and transplanting experiment}

The seedling picking and transplanting experiment was been completed using peppers as the experiment objects. A soft-plastic tray was used for the experiment, and the top and bottom of each square hole were $37 \mathrm{~mm} \times 37 \mathrm{~mm}$ and $18 \mathrm{~mm} \times 18 \mathrm{~mm}$, respectively. The depth of each hole was $45 \mathrm{~mm}$, and the diameter at the bottom of the hole was $10 \mathrm{~mm}$. Thin cayenne pepper seedlings were used in the experiment. The seedlings were 65 days old, the average height of the seedling was $150 \mathrm{~mm}$, and one seedling was transplanted into each hole. The pepper seedling was raised in composite substrates, and the moisture content was $13.3 \%$, containing turf soil, clay, perlite and mushroom residue. To improve the reliability of the transplanting mechanism and ensure that the seedling-picking clamp can successfully extract the potted vegetable seedling out of the tray, the 3D models (material is PLA) of key components related to seedling picking, such as the seedling-picking clamp, cam, fork and the seedling-pushing rob, were replaced with metal components. As shown in Figure 11, the seedling picking and seedling transplanting experiments were completed. The potted vegetable seedling transplanting is a systematic project. The core of transplanter is the transplanting mechanism, which includes not only the transplanting mechanism but also soil covering and pressing devices. In this research, transplanting experiments have been carried out for the potted vegetable seedling transplanting mechanism, without considering conventional techniques such as soil covering and pressing. The experiment showed that the potted vegetable seedling transplanting mechanism can separate the potted vegetable seedlings from the tray and plant them into the hole vertically. The success rate of seedling picking was $92.4 \%$. The potted vegetable seedling transplanting mechanism completed the actions of picking, transporting, punching the hole and transplanting in sequence, and all seedlings were transplanted into the hole punched by the shovel.

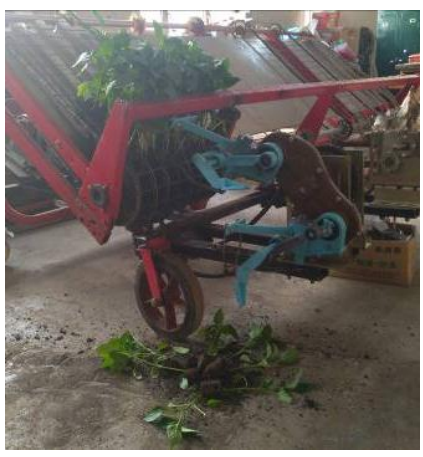

a. Seedling picking experiment

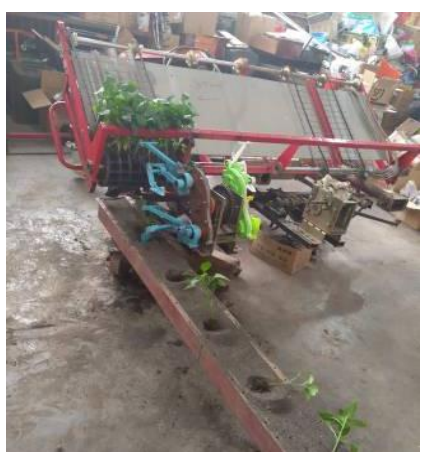

b. Seedling transplanting experiment
Figure 11 Seedling picking and transplanting experiment 


\section{Conclusions}

1) For the particular trajectory and attitude of potted vegetable transplanting, a fully automatic potted vegetable seedling transplanting mechanism with a punching device was developed, and the kinematics model was established. Additionally, the corresponding design theory and method were established to lay a theoretical foundation for the development of a vegetable seedling transplanting mechanism.

2) The agronomic requirements of the potted vegetable seedling transplanting were converted to numerical optimization objectives. The analysis and optimization software for the transplanting mechanism was developed to obtain a group of parameters that met the requirements of the vegetable pot transplanting mechanism.

3) The mechanism design was completed based on the optimized parameter, and the virtual prototype of the transplanting mechanism was established and simulated in the ADAMS software. The virtual simulation results show that the maximum error of attitudes of the transplanting arm is less than $1.19^{\circ}$ and that of the hole punching shovel is less than $1.7^{\circ}$.

4) The test bench of the transplanting mechanism was developed, and the verification experiment of the particular trajectory and attitude was conducted in combination with the high-speed photography technology. The results of the optimization software, virtual prototype simulation and the bench experiment were consistent, reciprocally verifying the correctness of the theoretical model, optimization software, virtual prototype and bench experiment.

5) The hole punching, seedling picking and transplanting experiments were completed, and the results indicated that the transplanting mechanism can complete the actions of picking, transporting, hole punching and transplanting. The success rate of seedling picking was $92.4 \%$. A series of experiments verified the validity and feasibility of the transplanting mechanism.

\section{Acknowledgements}

This research was supported by the National Key Research and Development Program of China (Grant No. 2017YFD070800), and the Opening of Key Laboratory of Modern Agricultural Equipment Technology in Northern Cold Region (Grant No. KF18-04).

\section{[References]}

[1] Yu X X, Zhao Y, Chen B C, Zhou M, Zhang H, Zhang Z. Current situation and prospect of transplanter. Transactions of the CSAM, 2014; 45(8): 44-53. (in Chinese)

[2] Wang X D, Feng J. State and development of transplanting mechanization with mulch film at home and abroad. Chinese Agricultural Mechanization, 2005; 3: 25-28. (in Chinese)

[3] Prasanna Kumar G V, Raheman H. Vegetable transplanters for use in developing countries - A review. International Journal of Vegetable Science, 2008; 14(3): 232-255

[4] Yu X T, Hu L L, Hu Z C. Development trend and general Situation of nonirrigated farmland transplanting mechanization in China. Journal of Anhui Agricultural Science, 2012; 40(1): 614-616. (in Chinese)

[5] Prasanna Kumar G V, Raheman H. Development of a walk-behind type hand tractor powered vegetable transplanter for paper pot seedlings.
Biosystems Engineering, 2011; 110(2): 189-197.

[6] Prasanna Kumar G V, Raheman H. Automatic feeding mechanism of a vegetable transplanter. Int J Agric \& Biol Eng, 2012; 5(2): 20-27.

[7] Gutiérrez C, Serwatowski R, Gracia C, Gracia C, Cabrera J M, Saldaña N Design building and testing of a transplanting mechanism for strawberry plants of bare root on mulched soil. Spanish Journal of Agricultural Research, 2009; 7(4): 791-799.

[8] Zhao X, Ren G Y, Chen J N. Kinematic analysis and experiment study of elliptic-gear and crank-rocker beating-up mechanism. Journal of Donghua University, 2011; 28(2): 222-225. (in Chinese)

[9] Zhao X, Chen J N, Wu J W. Kinematics modeling and analysis of deformed elliptic geared seven-bar linkage plant setting mechanism. China Mechanical Engineering, 2013; 24(8): 1001-1007. (in Chines)

[10] Jin X, Li D Y, Ma H, Ji J T, Zhao K X, Pang J. Development of single row automatic transplanting device for potted vegetable seedlings. Int $\mathrm{J}$ Agric \& Biol Eng, 2018; 11(3): 67-75.

[11] Feng Q C, Zhao C J, Jiang K, Fan P F, Wang X. Design and test of tray-seedling sorting transplanter. Int J Agric \& Biol Eng, 2015; 8(2): 14-20.

[12] Yu G H, Chen Z W, Zhao Y, Sun L, Ye B L. Study on vegetable plug seedling pick-up mechanism of planetary gear train with ellipse gears and incomplete non-circular gear. Journal of Mechanical Engineering, 2012; 48(13): 32-39. (in Chinese)

[13] Yu G H, Yu T F, Ye B L. Research on a new planetary gear train mechanism. Journal of Mechanical Engineering, 2013; 49(15):55-61. (in Chinese)

[14] Wang Y W, He Z L, Wang J, Wu C Y, Yu G H, Tang Y H. Experiment on transplanting performance of automatic vegetable pot seeding transplanter for dry land. Transactions of the CSAE, 2018; 34(3): 19-25. (in Chinese)

[15] Wang Y W, Tang Y H, Wang J, Cheng Z M. Parameter's optimization for the dibble-type planting apparatus of vegetable pot seeding transplanter in high-speed condition. Transactions of the CSAM, 2016; 47(1): 91-100. (in Chinese)

[16] Ye B L, Liu A, Yu G H. Parameters optimization with human-computer interaction method and experiment of vegetable seedling pick-up mechanism. Transactions of the CSAM, 2013; 44(2): 57-62. (in Chinese)

[17] Ye B L, Yi W M, Yu G H, Gao Y, Zhao X. Optimization design and test of rice plug seedling transplanting mechanism of planetary gear train with incomplete eccentric circular gear and non-circular gears. Int J Agric \& Biol Eng, 2017; 10(6): 43-55.

[18] Yu Y X, Luo C X, Yu G H. Parameters optimization of pick-up mechanism of planetary gear train with ellipse gears and incomplete non-circular gear. Transactions of the CSAM, 2013; 44(6): 62-68. (in Chinese)

[19] Zhou M L, Sun L, Du X Q, Zhao Y. Optimal design and experiment of rice pot seedling transplanting mechanism with planetary Bezier gears. Transactions of the ASABE, 2014; 57(6): 1537-1548.

[20] Zhou M L, Zhang Y H, Wang J Y. New type of transverse moving box mechanism for pot seedling transplanting machine. Int $\mathbf{J}$ Agric \& Biol Eng, 2018; 11(2): 70-75.

[21] Wang M M, Song J N, Liu C L. Design and experiment of crank rocker type clamp seedlings mechanism of vegetable transplanter. Transactions of the CSAE, 2015; 31(14): 49-57. (in Chinese)

[22] Cui W, Fang X F, Zhao L. Structural optimization and experimental verification of geared five-bar linkage seedling pick-up device. Transactions of the CSAM, 2013; 44(8): 74-77. (in Chinese)

[23] Liu J D, Cao W B, Tian D Y, Tang H Y, Zhao H Z. Kinematic analysis and experiment of planetary five-bar planting mechanism for zero-speed transplanting on mulch film. Int J Agric \& Biol Eng, 2016; 9(4): 84-91.

[24] Orzolek M D. Stand establishment in plasticulture systems. Horttechnology, 1996; 6(3): 181-185.

[25] Han L, Mao H, Hu J, Tian K. Development of a door frame-typed swinging seedling pick-up device for automatic field transplantation. Spanish Journal of Agricultural Research, 2015; 13(2): 1-14. 